\title{
New Algorithm for Fast Processing RFID System in Container Terminal
}

\author{
Evizal Abdul Kadir ${ }^{1,2}$, Siti Mariyam Shamsuddin ${ }^{1}$, Detri Karya ${ }^{2}$, Sri Listia Rosa ${ }^{2}$ \\ ${ }^{1}$ Big Data Centre, Faculty of Computing, Universiti Teknologi Malaysia, 81310, Johor, Malaysia \\ ${ }^{2}$ Department of Informatics, Faculty of Engineering, Universitas Islam Riau, Pekanbaru, Riau 28282, Indonesia
}

\begin{abstract}
Article Info
Article history:

Received Jun 2, 2015

Revised Oct 25, 2015

Accepted Nov 16, 2015

\section{Keyword:}

Algorithm

Container terminal

CTMS

RFID

ABSTRACT

The growth of world economic and increasing of trading in most of countries has impact to the number of containers export and import between countries. Some of container terminal is very busy to handle high volume of container movement. Conventional operational procedures have difficulties to handle containers movement then make slow and some issues in terminal operation for container clearance. This paper discus on proposing new algorithm to the current container terminal management system used RFID technology for fast processing and clearance. Container Terminal Management System (CTMS) is a system for port management and interface to the RFID system that used to identify container e-seal, truck and driver identity. Lack of communication and interfacing protocol made slow response during request or reply of message to the gate operator. Proposed algorithm with new procedure of request to CTMS made faster response and avoid inaccuracy of detecting container e-seal. Results of implementation new algorithm have improved to the productivity and efficiency of container terminal. Testing and implementation of this proposed system conducted in a private container terminal in Malaysia.
\end{abstract}

Copyright (c) 2016 Institute of Advanced Engineering and Science. All rights reserved.

Corresponding Author:

Evizal Abdul Kadir, Big Data Centre, Faculty of Computing

Universiti Teknologi Malaysia,

81310, Johor, Malaysia.

Email: evizal@gmail.com

\section{INTRODUCTION}

Container terminal is one of the ports used by freight forwarder to deliver goods, most of suppliers used container to sending product to the customer. A container terminal normally to serve international cargo and sea freight is the busiest terminal for container export/import. Number of world trading keeps increasing every year, some of container port out of capacity to handle container movement export and import or transshipments. Global container trade is projected to grow by $5.6 \%$ in 2015, driven among others by improved prospects for mainline East-West trade. Shipping lines is carry estimate 52 \% from total container in global trade by seaborne according by United Nations Conference on Trade and Development 2014 data [1], this because of more goods and product to be send such as fruit, meat, fish, etc and development of world trading. The use of technology in container terminal operations gives satisfaction to the customer or owner of container that can be trace almost anywhere at any time.

Implementation of Information and Communication Technology (ICT) into the container terminal operation system and RFID technology have been done for some of container ports in the world a few years ago, the use of technology in terminal operation gives efficiency and saving operational cost. Some issues are still facing and need further continuous improvement to achieve smooth operational system. Today, most of container ports in the world using ICT in operational system, some of ports equipped with RFID technology in order to capture container e-seal, according to the world shipping council top 20 container ports using 
RFID technology for container tagging [2]. Linkage of each terminal to others container terminal that use same technology make more efficient and fast in clearance, thus all parties are advises to do standardization and use same technology in order to match the system. In future, the trend is all ICT bases for container terminal operation system to support and secure to handle container.

Previous research works have been discussed on the use of ICT and RFID technology into container terminal management system for efficient and faster operational procedure also to improve of productivity in terminal operation. Establishment of Containers Terminal Management System (TCMS) based on RFID technology, proposed container management system consists of three main aspects: tracing, scheduling, allocation, and distribution during transportation; RFID database and Electronic Data Interchange (EDI). Result shows be able on real-time management into reality by the containers' information transmitted to a public platform [3]. Implementation of RFID technology in Jebel Ali Port United Arab Emirates (UAE) in order to increase reliability and efficiency of port operational as discussed on [4]. Each of container where tagged by RFID tag that can help in real-time identification and tracking of containers. The authors focused on tagging of container for tracking and identification for fast to find container and avoid human error and also security aspect when container sending out of container port area.

Application of Information Technology (IT) into the container terminal as discussed, where case investigation used pervasive computing technologies of RFID for Real Time Locating System (RTLS) and also mesh network for container terminal efficiency. Main objective of the report is to locate container location based on RFID tag at container [5]. In this report [6] proposed on Container Security Initiative (CSI) of the Electronic Container Seal (E-Seal), the basic technical features of active RFID systems are described and linked to the practical applications. Author mentions the applicable of the use E-Seal but never mention on specific implementation on container terminal.

In others work related the container management system are presented, moreover paper discussed on the use of RFID technology in container terminal for tracking and allocation of container in yard area and also the used of RFID technology for container traceability [7-9]. Algorithm and scheduling of container planning is discussed and simulation of optimization container clearance in temporary place or storage in yard area to achieve faster container movement, another paper also discussed on integration and optimization of container scheduling used Particle Swarm Optimization (PSO) in container terminal [10-13]. The used of RFID technology in container terminal because of advantages of that technology in order to capture multiple information in many objects, high throughput of RFID reader and anti collision protocol and algorithm as discussed, emerging of EPC global network and RFID technology for privacy of information and sensor tag middleware for container monitoring in logistics port system [14-17].

\section{RFID SYSTEM IN CONTAINER TERMINAL}

Proposed implementation of ICT system in a container terminal is done at a container port, the terminal service mostly for container export and import of goods because the terminal is located in country border area. Figure 1 shows picture taken at container terminal gate-in for receiving container to send to yard area or holding area then send to vessel for export. Gate-in container terminal has 6 lanes and implementation of ICT system with RFID technology into port operation expected to solve or overcome current issues that currently facing. The used of Information Technology (IT) is currently operating in planning department for container plan, management, and registration. System called Container Terminal Management System (CTMS) to serve for container planning, arrangement, storage in yard area and also planning for loading in vessel including container registration and request pick-up for forwarder agent. Development and extension of current ICT system to terminal gate for container clearance is very high impact in operational system. Implementation of system is to follow standardization that have been implemented in other ports worldwide then be able to overcome and solve some issues in operation such as:

- $\quad$ Reduce long queue at gate-in or receiving area.

- $\quad$ Real time update of container information into system, once RFID tagged at container to enter receiving gate.

- Improve efficiency of container clearance and real time authentication at receiving gate-in.

- $\quad$ Reduce manpower and operation staff.

- $\quad$ Provide real time visibility of container status.

- Improve customer service by fast clearance at receiving.

- Improve security of container by using e-seal.

- Scalable to extend service to other ports.

- Online access of container status in real time 


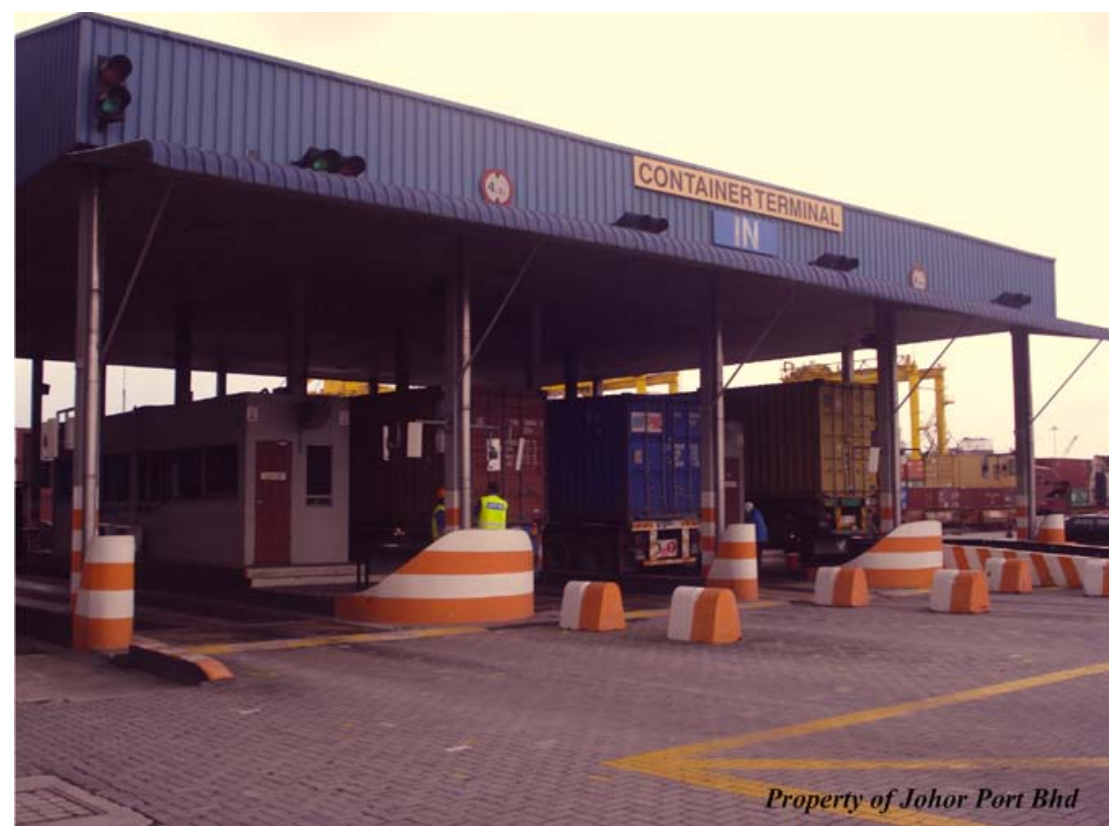

Figure 1. Container gate-in at one of port in Malaysia

Current operational procedure in receiving container at gate-in take much times because many step that need to perform by truck driver and pass the document manually which need to go to container receiving office (booth). Figure 2 shows example of a lane that normally used by truck driver to process container in order to pass to yard area or unloading bay. Once truck arrived and parking on weight balance then truck driver go down to unlock container as in figure 2 shown indicate number 1 , after that continue unlock all the container from chassis to make sure when container picking-up by Rubber Tires Gantry (RTG) crane is freely. All the process to unlock until number 6 normally take average 100 seconds for back to back or double 20 footer container and 80 seconds for single container either 20 footer or 40 footer. Next procedure is number 7 to give gate pass from forwarder office to container staff then key-in into system, all the information such as driver name by shows Identity Card (ID), truck or vehicle registration number, tally all the information, weight checking confirmation and check cargo. Beside that another staff outside the office to check container physically to make sure seal bolt is in good condition, container never tampered or leakage, after everything is done then officer will conform and print a ticket for information of unloading area at Rubber Tire Gantry (RTG) crane. If anyone of information or physical condition of container is fail or overweight and also some cases no pre-advise registration been done by forwarder then the officer instruct truck or cargo to be hold by reverse and park at holding area until everything is matching. Average complete processing time is 3-4 minutes, especially for back to back container officer need to check and key double container information into CTMS system.

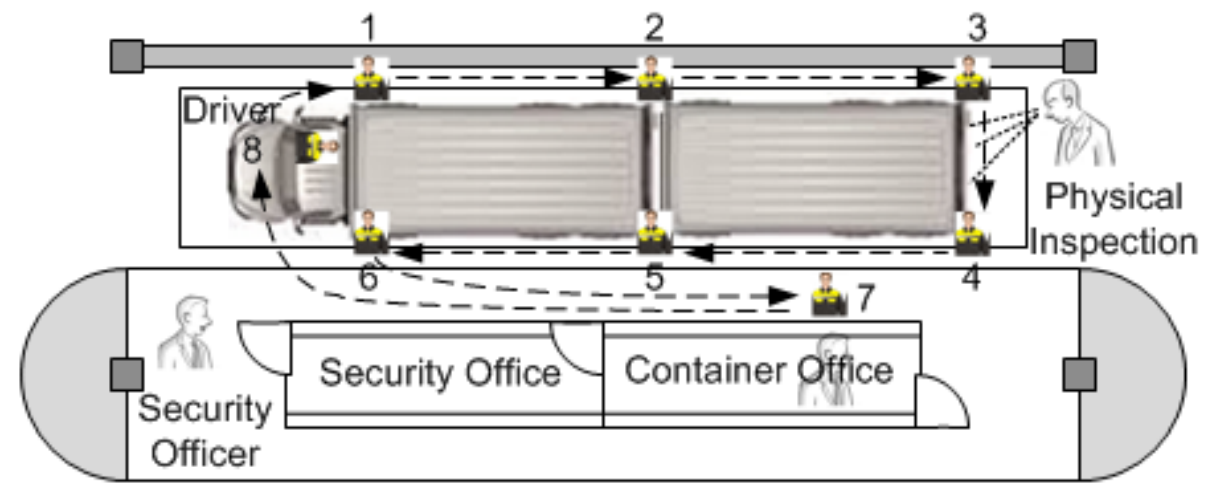

Figure 2. Procedure for receiving container at gate-in in terminal 


\section{PROPOSED NEW RFID ALGORITHM}

Proposed RFID system in container terminal operation used active tag type (e-seal) which ability for metallic and hazard environment as typical in container terminal. RFID active tag is powered by a battery that can be used as a partial or complete source of power for the tag's circuitry. Some active tag battery capable for replaceable of several years of use, and some others are sealed unit that difficult to replaceable and prepare for one cycle use. A single active RFID reader is able to read the information and collect the data from the tag more than one hundred of tags, also be able to read the tag in speed up to 100 kilometers/hour. Active tags memory have much larger data storage and transmit or receive capacities, and also able to equipped by others sensor such as temperature, humidity, vibration, and pressure [18].

RFID middleware as function to serve client which is gate checker tablet, then received information from RFID readers and sensor to process and verify to CTMS system. Initial testing middleware received many information which tags ID and e-seal ID with container number, then middleware unable to verify tags ID belong to which lane (multiple lanes testing). Thus, some adjusting and fine tuning RFID reader gives result middleware can be identify tags ID come from which lane. Testing and trial continue and another issues is too many unnecessary data because reader keep reading and sending data to middleware although there is no vehicle or truck go into container receiving lane (tags belong people or others pass thru the area). The solutions is by filtering and clearing buffer data on the middleware is required to avoid dumping data for next transaction of container clearance, beside that an algorithm is proposed to enhancement data processing for smooth and fast processing time.

Messaging structure and flow between RFID middleware and CTMS is implementing in order to achieve effective communication and fast processing because CTMS as central database for container terminal also serve information to other parties. RFID middleware messaging also for communication to gate checker, initial request is from gate checker according lane number in gate-in. All messaging are ASCIIbased, with START and END delimiters. The middle token is presumed to represent EMPTY or NULL or NON-APPLICABLE fields. Table 1 shows token code and symbol for communication both systems.

Table 1. RFID System Token

\begin{tabular}{ccc}
\hline Token type & ASCII & Printable Code \\
\hline Start Token & 26 & $->$ (single char) \\
End Token & 27 & $<-$ (single char) \\
Middle Token & 29 & $x$ (not visible) \\
\hline
\end{tabular}

The Gate Checker initiates ALL transactions with the RFID middleware software interface. Only four (4) messages are applicable to the RFID interface software, these are messages R01, R04, CK and CK8. Figure 3 shows a flowchart of complete algorithm in RFID middleware to process data from RFID reader in multiple lanes [19].

Algorithm shows RFID reader only start when get instruction or command from photoelectric sensor, then sensor activated if any truck is coming (sensor adjusted to detect only truck with high level setting). Once gate checker request indicated in which lanes then middleware reply tags ID driver and vehicle, in this step gate checker may request in different time thus dotted lines on flowchart indicated gate checker request in different time in example, but middleware keep data in buffer until complete transaction, in this step active RFID reader start retrieve information for e-seal. If middleware received information from RFID reader then reply by acknowledgment that information is received, verification of driver, vehicle, eseal and container number need to be done on CTMS system because middleware does not keep any database. Once information is tally to the pre-registration that input by forwarding agent then middleware send message to gate checker for validation and confirmation else a pop-up message send as "Driver and Truck ID Not Found”. If everything is fine including container checking and inspection then gate checker confirmation transactions and a ticket print out for driver direction information. Second photoelectric sensor at the back of lane is to stop RFID reading and close for this transaction once is activated. The algorithm has more advantages compare than basic redundancy filtering algorithm in data filtering. The common problems in the RFID system is solved after the e-seal data is processed by improved noise redundancy filtering algorithm and the data filtering algorithm based system token on table. The adaptive operator and time window are introduced in this testing on the basis of basic noise filtering algorithm. The window of the adaptive noise filtering algorithm is put in forward [20]. 


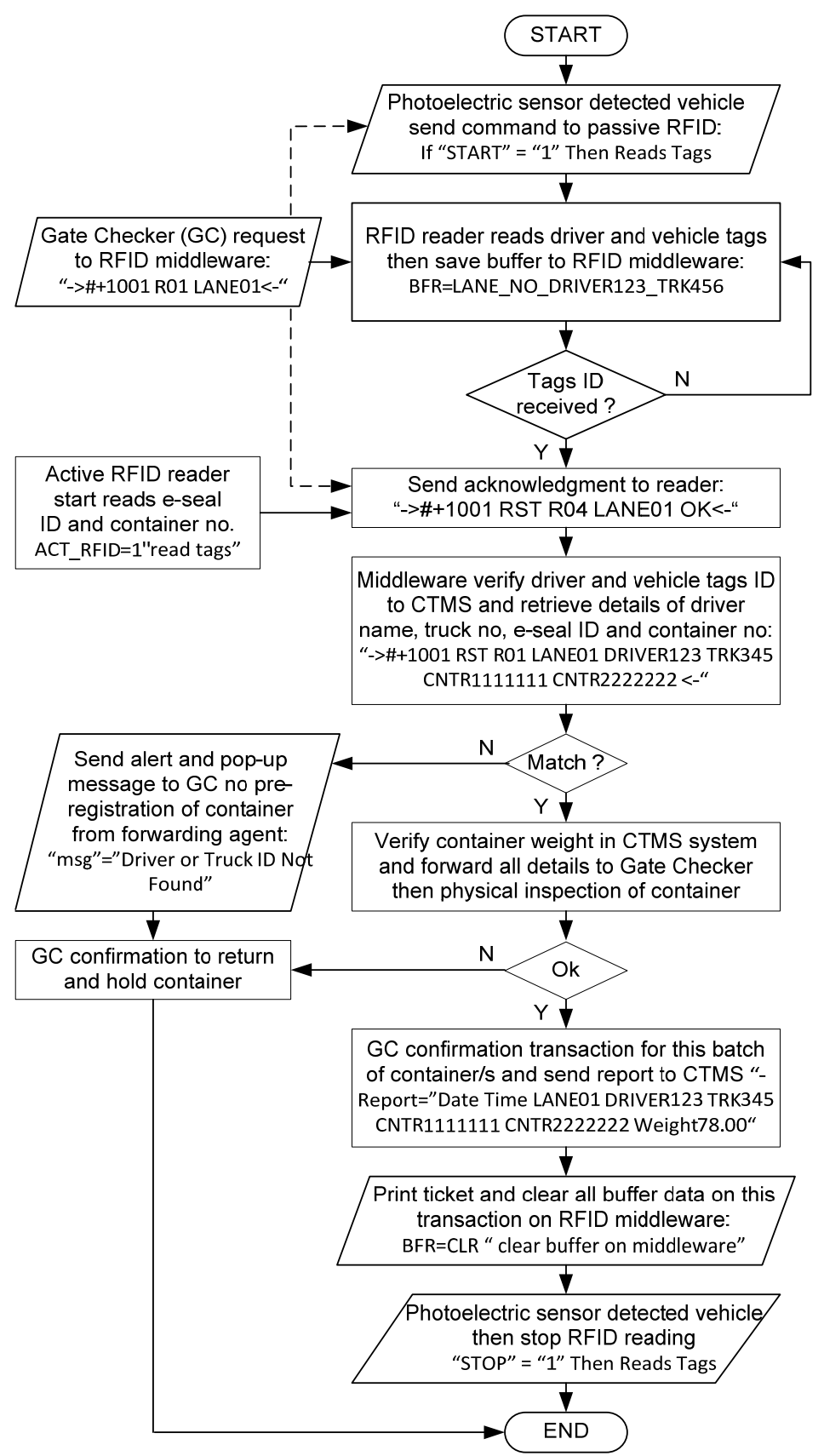

Figure 3. Complete algorithm flowchart of RFID middleware

\section{EVALUATION RESULTS}

Initial testing of proposed the use ICT and RFID technology in container terminal conduct at container receiving gate-in, configuration and architecture of hardware and complete network also communication to container terminal system. Testing have been done by placing driver and vehicle tag on truck then e-seal at the back of container, in this initial stage all tags and e-seal used passive type and single lane of container receiving, results obtain is RFID reader achieve to capture of RFID tag ID and information with RFID reader power transmits set to maximum. Second stage of testing is with multiple lanes to check reading performance of RFID reader which is lane-3 and 4 that very close to each other. Results shows multiple tags ID capture by reader and do not know from which reader because lane-3 RFID reader over reading to driver and vehicle tags of truck at lane-4 and vise versa RFID reader lane-4 reads tags on the lane3 , this happen because of reader power transmits to high. Next testing is to adjust reader transmits power lower to just read of coverage area in specific lane within a few meters, this level all driver and vehicle tags can read according to the truck in lane and over reading to adjacent lane issue is solve. Another issue is 
facing on the e-seal reading because power of reader reduced then reading performance on the e-seal at the back of container is not good because of environment with high level metal. Figure 4 shows average processing time used with new algorithm per container.

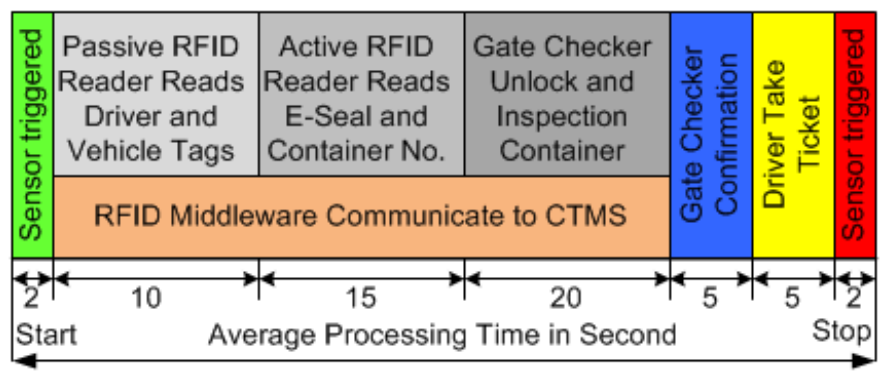

Figure 4. Average processing time in new algorithm

The use of e-seal with active RFID type for better reading performance as currently used in Shanghai Port which is e-seal with $2.4 \mathrm{GHz}$, where every protocols and interfaces used same standard that expected this e-seal can be reads by Shanghai Port RFID system then system able to communicate for better service to customers and also to promote the use of RFID e-seal to others container terminal worldwide. The design of active RFID e-seal is similar to the design of mechanical container seal with bolt to lock and this eseal has sensor, once seal is unplug or open without authorize there is tampered record in the e-seal. Testing on active RFID e-seal does not many issues because active RFID can read in longer range but some additional equipment for active RFID reader. This version of e-seal as final for this implementation and results shows performance of container clearance is better and great improvement.

RFID middleware as function to serve client which is gate checker, then received information from RFID readers and sensor to process and verify to CTMS system. In initial testing, middleware received many information which is tags ID and e-seal ID with container number, then middleware unable to verify tags belong to which lane (multiple lanes testing). Thus, some adjustment and fine tuning of RFID reader give results that middleware can be identify tags ID come from which lane. Testing continues and another issue facing is too many unnecessary data because reader keep reading and sending data to middleware, although there is no vehicle or truck in receiving lane (tags belong to others pass thru the area). This issue solve by limit the time of reading RFID reader but system cannot recognize whether truck on the lane or not, thus this step need involve in hardware system by install photoelectric sensor in front and end of lane for start and stop reading of RFID reader. Clearance (processing) time data are taken from several container come into the lane with several type of container such as 20 foot, 40 foot and double 20 foot container. Table 2 shows the results of container clearance time between previous manual procedure to new procedure with ICT and RFID system. Results shows very great enhancement and time saving compare to previously, in previous procedure average clearance time is 248.1 second (+/- 4 minutes) and new procedure average time is 57 (+/- 1 minute) second or enhancement up to $77 \%$ time saving.

Table 2. Clearance time comparison between previous procedures to new ICT implemented procedure

\begin{tabular}{cccccc}
\hline \multirow{2}{*}{ No } & Data & Previous & \multicolumn{3}{c}{ Container Type (foot) } \\
& Collection & Procedure & $\mathbf{2 0}$ & $\mathbf{2 0 + 2 0}$ & $\mathbf{4 0}$ \\
\hline 1 & $1^{\text {st }}$ Container & $250 \mathrm{sec}$ & 40 & 65 & 61 \\
2 & $2^{\text {nd }}$ Container & $215 \mathrm{sec}$ & 43 & 75 & 52 \\
3 & $3^{\text {rd }}$ Container & $296 \mathrm{sec}$ & 55 & 78 & 72 \\
4 & $4^{\text {th }}$ Container & $260 \mathrm{sec}$ & 40 & 61 & 55 \\
5 & $5^{\text {th }}$ Container & $220 \mathrm{sec}$ & 35 & 69 & 60 \\
6 & $6^{\text {th }}$ Container & $289 \mathrm{sec}$ & 59 & 65 & 62 \\
7 & $7^{\text {th }}$ Container & $192 \mathrm{sec}$ & 50 & 71 & 70 \\
8 & $8^{\text {th }}$ Container & $266 \mathrm{sec}$ & 51 & 55 & 46 \\
9 & $9^{\text {th }}$ Container & $236 \mathrm{sec}$ & 40 & 63 & 48 \\
10 & $10^{\text {st }}$ Container & $257 \mathrm{sec}$ & 52 & 65 & 53 \\
Average Time (sec) & $\mathbf{2 4 8 . 1}$ & $\mathbf{4 6 . 5}$ & $\mathbf{6 6 . 7}$ & $\mathbf{5 7 . 9}$ \\
\hline
\end{tabular}


Currently, most of container terminal operation is based on manual or semi-automation system that employs ICT technology to assist in operation. Although in some of terminal has introduced ICT technology in operation but yet implement proper procedure and software management (algorithm) thus operation still not achieve in optimum productivity. Proposed new technology and algorithm in order to improve container terminal operation has a tremendous results and improvement in term of time and productivity. As shows in table 2 comparison between previous process time and new processing time, the others impact by introduced ICT technology in terminal operations is smart terminal operation. Table 3 shows a comparison current procedure in container terminal operation to new proposed system in various effects and improve productivity and efficiency.

Table 3. Comparison previous system to proposed new technology in container terminal

\begin{tabular}{|c|c|c|}
\hline Description & Previous Operations System & Proposed New System \\
\hline ICT technology used & $\begin{array}{l}\text { Yes, but not optimum without implement } \\
\text { algorithm in software operation }\end{array}$ & $\begin{array}{l}\text { Yes, implement algorithm in software } \\
\text { management thus high productivity achieve }\end{array}$ \\
\hline Forwarder vehicle / trailer & $\begin{array}{l}\text { Without e-seal, driver and vehicle ID and } \\
\text { GPS }\end{array}$ & $\begin{array}{l}\text { Introduced e-seal for container, driver and } \\
\text { vehicle RFID tag for identification and GPD } \\
\text { for locating system }\end{array}$ \\
\hline Prime mover in terminal & $\begin{array}{l}\text { Used handy talky to communicate and } \\
\text { manual record by checklist }\end{array}$ & $\begin{array}{l}\text { Used Vehicle Mounting Technology Table } \\
\text { then all online record for any container } \\
\text { transaction in yard or wharf }\end{array}$ \\
\hline Gate checker in / out terminal & $\begin{array}{l}\text { Manual entry by operator or receiving } \\
\text { staff then input to the system }\end{array}$ & $\begin{array}{l}\text { Introduced RFID system to scan container e- } \\
\text { seal and tag then receiving staff used tablet } \\
\text { to do transaction and confirmation }\end{array}$ \\
\hline Forwarder gate pass & Used manual receipt and manual writing & $\begin{array}{l}\text { Used e-seal and information send via web } \\
\text { page online in advanced before container } \\
\text { reach terminal }\end{array}$ \\
\hline Container tracking and monitoring & $\begin{array}{l}\text { Unable to track and monitor container } \\
\text { position because there no identification } \\
\text { system }\end{array}$ & $\begin{array}{l}\text { Enable to do tracking and monitoring of } \\
\text { container because GPS is embedded in } \\
\text { vehicle }\end{array}$ \\
\hline
\end{tabular}

\section{CONCLUSION}

New algorithms for effective operation in container terminal have been implemnted into RFID middleware. RFID equipmennts are installed at gate-in of container receiving area, every container registered with e-seal will capture by RFID reader the information inside e-seal will send to middleware then CTMS for verification. Several testing and trial have been conducted to find best position and location of RFID equipments, and the best position fixed at container receiving site and RFID equipments installed for every lanes, one set for each lane. Proposed new algorithm assits RFID middleware software to select necessary data is very important for effective processing time. Filtering process of e-seal ID and shipment information before sending to middleware and CTMS to avoid noise data received by middleware is controlled by proposed new algorithm. Results shows great improvements and fast processing time of RFID system and no more noise or unused data received on middleware. In overal impact to the container terminal system are reduce truck and waiting queue at receiving area and improve productivity of container terminal. Customer satisfaction is one of the benefits to introduce this system to the container terminal and future enhancement to improve other parts that posibility to increasing for efficiency in container terminal operation.

\section{ACKNOWLEDGEMENTS}

This work was supported under MOHE Research Group Flagship Grant Q.J130000.2428.02G38 “Predictive Analytics Framework for E-Learning Big Data Computing”.Big Data Centre, Faculty of Computing, Universiti Teknologi Malaysia.

\section{REFERENCES}

[1] U. Nations, "Review of Maritime Transport", United Nations Conference on Trade and Development, 2013.

[2] M.H. Hakam and W.D. Solvang, "RFID communication in container ports", in Cognitive Infocommunications (CogInfoCom), 2012 IEEE 3rd International Conference on, 2012, pp. 351-358.

[3] K. Xianwen, Z. Hao, J. Nan, W. Xiaoxia, and Z. Jianjun, "Establishment of Containers Management System Based on RFID Technology", in Computer Science and Software Engineering, 2008 International Conference on, 2008, pp. 329-331. 
[4] M.K. Watfa, U. Suleman, and Z. Arafat, "RFID system implementation in Jebel Ali port", in Consumer Communications and Networking Conference (CCNC), 2013 IEEE, 2013, pp. 950-955.

[5] K. Kap Hwan and B.H. Hong, "Maritime logistics and applications of information technologies", in Computers and Industrial Engineering (CIE), 2010 40th International Conference on, 2010, pp. 1-6.

[6] C. Le-Pong and W. Chia-Lin, "The Role of Electronic Container Seal (E-Seal) with RFID Technology in the Container Security Initiatives", in MEMS, NANO and Smart Systems, 2004. ICMENS 2004. Proceedings. 2004 International Conference on, 2004, pp. 116-120.

[7] C. Zhang, T. Wu, K.H. Kim, and L. Miao, "Conservative allocation models for outbound containers in container terminals", European Journal of Operational Research, vol. 238, pp. 155-165, 2014.

[8] G. Azuara, J. Luis Tornos, and J. Luis Salazar, "Improving RFID traceability systems with verifiable quality", Industrial Management \& Data Systems, vol. 112, pp. 340-359, 2012.

[9] B. Song and Y. Cui, "Productivity changes in Chinese Container Terminals 2006-2011", Transport Policy, vol. 35, pp. 377-384, 2014.

[10] B. Cai, S. Huang, D. Liu, and G. Dissanayake, "Rescheduling policies for large-scale task allocation of autonomous straddle carriers under uncertainty at automated container terminals", Robot. Auton. Syst., vol. 62, pp. 506-514, 2014.

[11] P. Jean-François Cordeau, Rina Mary Mazza, Roberto Trunfio, "Simulation-based optimization for housekeeping in a container transshipment terminal", Computers \& Operations Research, vol. 53, 2015.

[12] H.J. Carlo, I.F.A. Vis, and K.J. Roodbergen, "Storage yard operations in container terminals: Literature overview, trends, and research directions", European Journal of Operational Research, vol. 235, pp. 412-430, 2014.

[13] Y. Lu and M. Le, "The integrated optimization of container terminal scheduling with uncertain factors", Computers \& Industrial Engineering, vol. 75, pp. 209-216, 2014.

[14] R. Ferrero, F. Gandino, B. Montrucchio, and M. Rebaudengo, "A Fair and High Throughput Reader-toReader Anticollision Protocol in Dense RFID Networks", Industrial Informatics, IEEE Transactions on, vol. 8, pp. 697-706, 2012.

[15] C. Yuan-Hsin, H. Shi-Jinn, R. S. Run, L. Jui-Lin, C. Rong-Jian, C. Wei-Chih, et al, "A Novel AntiCollision Algorithm in RFID Systems for Identifying Passive Tags", Industrial Informatics, IEEE Transactions on, vol. 6, pp. 105-121, 2010.

[16] B. Fabian, T. Ermakova, and C. Muller, "SHARDIS: A Privacy-Enhanced Discovery Service for RFIDBased Product Information", Industrial Informatics, IEEE Transactions on, vol. 8, pp. 707-718, 2012.

[17] K. Gihong, M.K. Uddin, and H. Bonghee, "Design and Implementation of Sensor Tag Middleware for Monitoring Containers in Logistics Systems", in Sensor Technologies and Applications, 2009. SENSORCOMM '09. Third International Conference on, 2009, pp. 393-398.

[18] T.A.R. Evizal., Sharul Kamal Abdul Rahim, "Active RFID Technology for Asset Tracking and Management System", TELKOMNIKA, Vol. 11, pp. 137-146, 2013.

[19] E.A. Kadir, S.M. Shamsuddin, S. Kamal Abdul Rahim, and S.L. Rosa, "RFID middleware for fast clearance in container terminal management system", in Information and Communication Technology (ICoICT ), 2015 3rd International Conference on, 2015, pp. 478-481.

[20] J.Z. Ming Ke, Mingming Huo, Xuhui Chen, "The Research and Implementation of RFID Middleware Data Filtering Algorithm", Research Journal of Applied Sciences, Engineering and Technology, Vol. 7, pp. 1075-1081, 2014.

\section{BIOGRAPHIES OF AUTHORS}

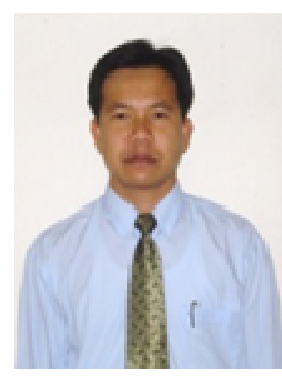

Evizal Abdul Kadir obtained his PhD in Wireless Communication from Universiti Teknologi Malaysia (UTM) Malaysia in 2014, M.Eng in Electrical/Electronis and Telecommunication Universiti Teknologi Malaysia (UTM) Malaysia in 2008. B.Eng in Electrical Engineering Bung Hatta University Indonesia in 1999. Currently, He is a Post Doctoral Fellowship in Big data Centre Faculty of Computing Universiti Teknologi Malaysia. He have been worked in several companies that provide system solution in telecommunication and radio frequency identification (RFID) in Malaysia, Singapore and Indonesia, He is continuing his research activity related to the wireless and mobile communication, radio frequency identification (RFID), RF microwave system, antenna design, computer system and networking, satellite communication and wireless sensor network (WSN). He has published a number of technical papers including journals and international conferences on antenna, RFID and intelligent system for industrial. 


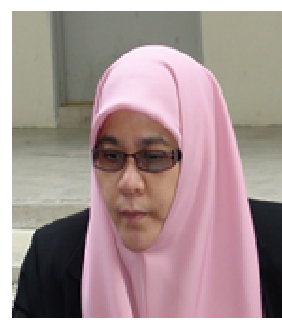

Siti Mariyam Shamsuddin received her BSc and MSc degree in Mathematics from New Jersey USA, and Phd in Pattern Recognition \& Artificial Intelligence from Universiti Putra Malaysia (UPM), MALAYSIA. Currently, she is a Director of UTM Big Data Centre, Universiti Teknologi Malaysia (UTM), Johor, Malaysia. Her research interests include the Data Computing, Soft Computing and its Application, Meta-Heuristic Algorithms, Pattern Recognition, Forensic Document Analysis, Geometric Modeling, and GPU Computing for Machine Learning. She has teaching experience in the area of mobile machine learning, pattern recognition, big data programming and intelligent modeling. He has published more than 120 papers related to machine learning, predictive analytics, data analytics in national/international journal and conferences. She can be reached at mariyam@utm.my or sitimariyams@gmail.com.

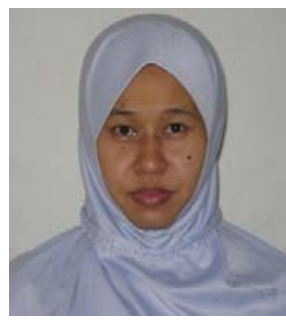

Sri Listia Rosa obtained her M.Sc. in computer science, faculty of computing Universiti Teknologi Malaysia in 2013 and B.Eng in electrical engineering from Bung Hatta University in 1999. Currently, She as lecturer in department of informatics, faculty of technology Islamic University of Riau. She research is on artificial immune system, intelligent system and immune system algorithm. She has published several papers including journals and international conferences on artificial immune system. 